\title{
Alkyl substituted 4-pyrrolidinopyridinium salts encapsulated in the cavity of cucurbit[10]uril
}

Weitao Xu, ${ }^{\mathrm{a}}$ Ming Liu, ${ }^{\mathrm{a}}$ Mary Clare Escaño, ${ }^{\mathrm{b}}$ Carl Redshaw, ${ }^{\mathrm{c} *}$ Bing Bian, ${ }^{\mathrm{d}}$ Ying Fan, ${ }^{\mathrm{a}}$ Zhu Tao, ${ }^{\mathrm{a}}$ and $\mathrm{Xin} \mathrm{Xiao}^{\mathrm{a} *}$

${ }^{a}$ Key Laboratory of Macrocyclic and Supramolecular Chemistry of Guizhou Province, Guizhou University, Guiyang 550025, China

${ }^{b}$ Research Center for Development of Far-Infrared Region, University of Fukui, Fukui 910-8507, Japan

${ }^{d}$ Chemistry, School of Mathematics and Physical Sciences, University of Hull, Hull HU6 7RX, U.K.

${ }^{c}$ College of Chemistry and Environmental Engineering, Shandong University of Science and Technology, Qingdao 266590, China.

\begin{abstract}
The interaction between cucuribit[10]uril (Q[10]) and a series of 4pyrrolidinopyridinium salts bearing aliphatic substituents at the pyridinium nitrogen, namely 4-( $\left.\mathrm{C}_{4} \mathrm{H}_{8} \mathrm{~N}\right) \mathrm{C}_{5} \mathrm{H}_{5} \mathrm{NRBr}$, where R = Et (g1), n-butyl (g2), n-pentyl (g3), $n$-hexyl (g4), n-octyl (g5), $n$-dodecyl (g6), has been studied in aqueous solution by ${ }^{1} \mathrm{H}$ NMR spectroscopy, electronic absorption spectroscopy and mass spectrometry. The results revealed that the guests g1-g5 are located completely inside the cavity differing only in the orientation of g1, g4 and g5 which are aligned with the portal, whilst g2 and g3 are perpendicular to it. For g6, the tetrahydropyrrole moiety remains outside of the portal. DFT calculations confirm the stability of the guests in the Q[10] and the possibility of their curved structure inside the Q[10].
\end{abstract}

Keywords: Cucuribit[10]uril; 4-pyrrolidinopyridinium salts; host-guest interaction; self-assembly; DFT calculations.

\section{Introduction}


There is continued interest in the chemistry of cucurbit $[n]$ uril $(\mathrm{Q}[n])$ systems given their excellent host-guest binding ability and resultant potential for a variety of applications. ${ }^{[1-10]}$ For example, systems incorporating Q[10] have been employed as supramolecular hydrogels, drug delivery agents, and its metal coordination chemistry is currently being explored. ${ }^{[11-22]}$ Of the $\mathrm{Q}[n]$ systems, curcurbit[10]uril (Q[10]) is still the largest prepared to date, and as such has the largest portals and cavity of all the $\mathrm{Q}[n]$ compounds. It is noteworthy though that our group has recently reported a series of twisted curcurbit[n]urils $(t \mathrm{Q}[n] \mathrm{s})$ constructed from a twisted oligomer which contain 13, 14 or 15 glycouril moieties. ${ }^{[23,24]} \mathrm{Q}[10]$ was first reported in a Q[5]-Q[10] form in $2002,{ }^{[25]}$ and was subsequently isolated via the use of 1,12 -dodecanediamine ${ }^{[26]}$ as ammeline ${ }^{[27]}$ and amantadine ${ }^{[28]}$ derivatives. Despite its isolation, the chemistry of $\mathrm{Q}[10]$ has been less well studied than that of other $\mathrm{Q}[n]$ s such as $\mathrm{Q}[7]$ and $\mathrm{Q}[8]{ }^{[29-34]}$ which is presumably due to low yield and/or difficulty in purifying the Q[5]-Q[10] form, or indeed problems isolating pure Q[10] prior to 2015 when Liu et al published their alternative and more efficient method. ${ }^{[25]}$ After more than 6 years of trying, we were finally able to isolate $\sim 10 \mathrm{~g}$ of pure $\mathrm{Q}[10]$ from $450 \mathrm{~g}$ of an insoluble $\mathrm{Q}[\mathrm{n}]$ mixture that included Q[6], iQ[6], Q[8] and Q[5]-Q[10]) using the one-pot method of Liu et al.

We are interested in the host-guest behaviour of $\mathrm{Q}[n] \mathrm{s}$, and have previously reported how $\mathrm{Q}[n]$ systems, where $\mathrm{n}=6$ and 8 , interact with a variety of pyridinium salts. ${ }^{\text {[35-38] }}$ Given the interest in 4-pyrrolidinopyridines as for example catalysts in acyl transfer reactions, ${ }^{[39-41]}$ we have focused on our recent studies on this type of guest. In the case of Q[6], we found that for $N$-butyl-4-pyrrolidinopyridine, only the butyl chain was 
found to reside in the cavity. ${ }^{[42]}$ We now extend our host-guest studies to the Q[10] system (see chart 1), and report our observations on its interaction with a series of 4pyrrolidinopyridinium salts, namely $4-\left(\mathrm{C}_{4} \mathrm{H}_{8} \mathrm{~N}\right) \mathrm{C}_{5} \mathrm{H}_{5} \mathrm{NRBr}$, where $\mathrm{R}=\mathrm{Et}$ (g1), $n$-butyl (g2), n-pentyl (g3), $n$-hexyl (g4), n-octyl (g5), n-dodecyl (g6), which are characterized by ${ }^{1} \mathrm{H}$ NMR and ${ }^{13} \mathrm{C}$ NMR (Figure S1-S6).
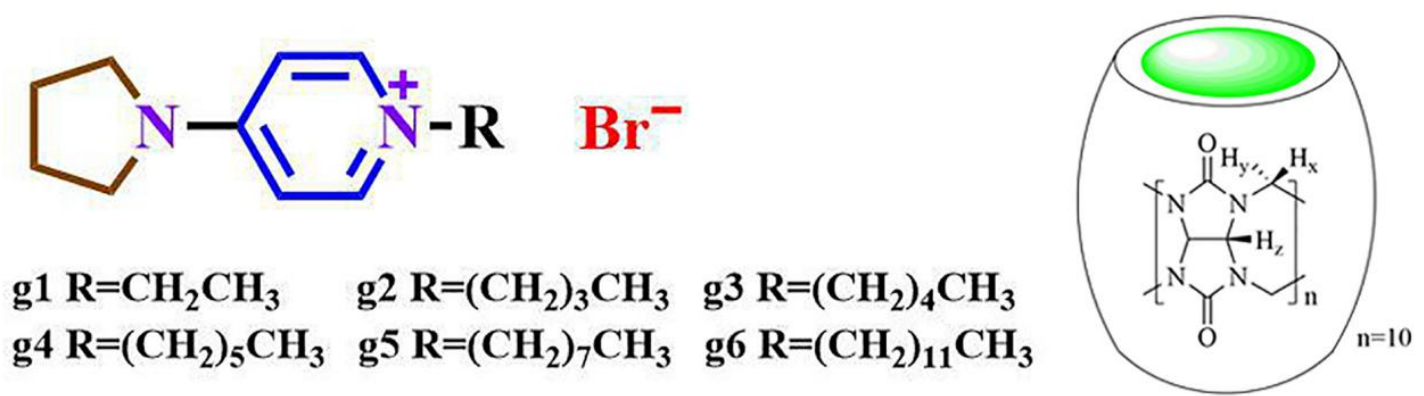

Chart 1. Guests and Q[10] used in this study.

\section{Results and Discussion}

\subsection{NMR spectroscopy}

The binding interactions between each of the pyrrolidinopyridinium guests and $\mathrm{Q}[10]$ can be conveniently monitored using ${ }^{1} \mathrm{H}$ NMR spectroscopic data recorded in neutral $\mathrm{D}_{2} \mathrm{O}$ solution. Figure 1 shows the changes observed in the ${ }^{1} \mathrm{H}$ NMR spectrum of g1 as progressively larger amounts of Q[10] are added to the solution. A slight up-field shift of the signals of the protons of the ethyl chain and a clear up-field shift of the signals of the protons of the pyridine and pyrrole rings was observed as Q[10] was added. At 1.00 equiv. of $Q[10]$, the resonances of protons $H_{e}$, and $H_{f}$ associated with the ethyl group exhibited up-field shifts of $0.38 \mathrm{ppm}$ and $0.37 \mathrm{ppm}$, respectively. The aromatic protons $\mathrm{H}_{\mathrm{c}}$ and $\mathrm{H}_{\mathrm{d}}$ of the pyridinium moiety were shifted up-field by $0.47 \mathrm{ppm}$ and 0.42 ppm respectively. The largest up-field shifts were experienced by the protons $\mathrm{H}_{\mathrm{a}}$ and 
$\mathrm{H}_{\mathrm{b}}$ of the pyrrolidino group at 0.50 and $0.58 \mathrm{ppm}$ respectively. These shifts indicate that the pyridinium, ethyl and pyrrole rings were all accommodated within the cavity of the $\mathrm{Q}[10]$ as represented by the cartoon representation top right of Figure 1.

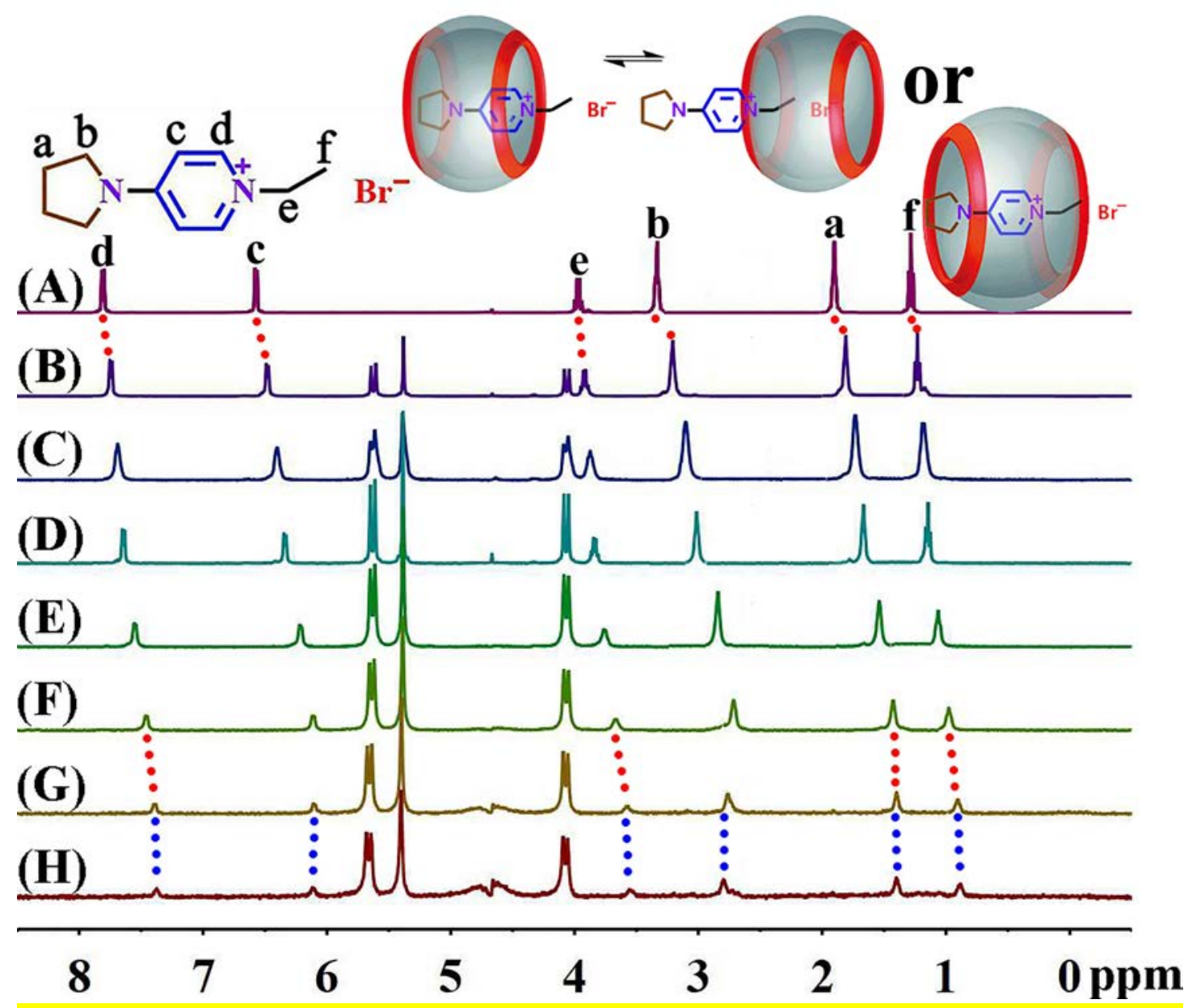

Figure 1. Interaction of g1 and $\mathrm{Q}[10]\left(20^{\circ} \mathrm{C}\right):{ }^{1} \mathrm{H}$ NMR spectra $\left(400 \mathrm{MHz}, \mathrm{D}_{2} \mathrm{O}\right)$ of g1 (ca. $2 \mathrm{mM}$ ) in the absence of $\mathrm{Q}[10]$ (A), in the presence of 0.090 equiv. of $\mathrm{Q}[10]$ (B), in the presence of 0.176 equiv. of $\mathrm{Q}[10](\mathrm{C})$, in the presence of 0.242 equiv. of $\mathrm{Q}[10]$ (D), in the presence of 0.408 equiv. of Q[10] (E), in the presence of 0.659 equiv. of $\mathrm{Q}[10](\mathrm{F})$, in the presence of 1.001 equiv. of $\mathrm{Q}[10](\mathrm{G})$, and in the presence of 1.273 equiv. of $\mathrm{Q}[10](\mathrm{H})$.

Figure 2 shows the ${ }^{1} \mathrm{H}$ NMR titration spectra of g2 in $\mathrm{D}_{2} \mathrm{O}$ recorded in the absence of $\mathrm{Q}[10]$ (A) and with increasing proportions of $\mathrm{Q}[10]$ at 0.169 (B), 0.330 equiv. (C), 
0.565 equiv. (D), 0.963 equiv. (E), and 1.372 equiv. (F) at $20{ }^{\circ} \mathrm{C}$. Noticeably up-field shifts were observed for all the protons of the pyridine ring, pyrrole ring and alkyl chain as Q[10] was added. On addition of one equivalent of Q[10] all peaks had shifted by > $0.37 \mathrm{ppm}$ compared to their positions in free g2, with the largest shift observed for $\mathrm{Hg}$ at $0.68 \mathrm{ppm}$ (from 1.13 to $0.45 \mathrm{ppm}$ ). This indicates that the pyridine ring, the pyrrole ring and the alkyl chain are all accommodated within the cavity of Q[10]. The changes observed in the chemical shifts for all the protons of g3 are similar to those of g2 as Q[10] was added. As shown in Figure S7, obvious up-field shifts for all the protons of the pyridine ring, the pyrrole ring and the alkyl chain were observed (shifts were in the range 0.34 to $0.77 \mathrm{ppm}$ ) as the Q[10] was added, which indicates the situation is as for g2.

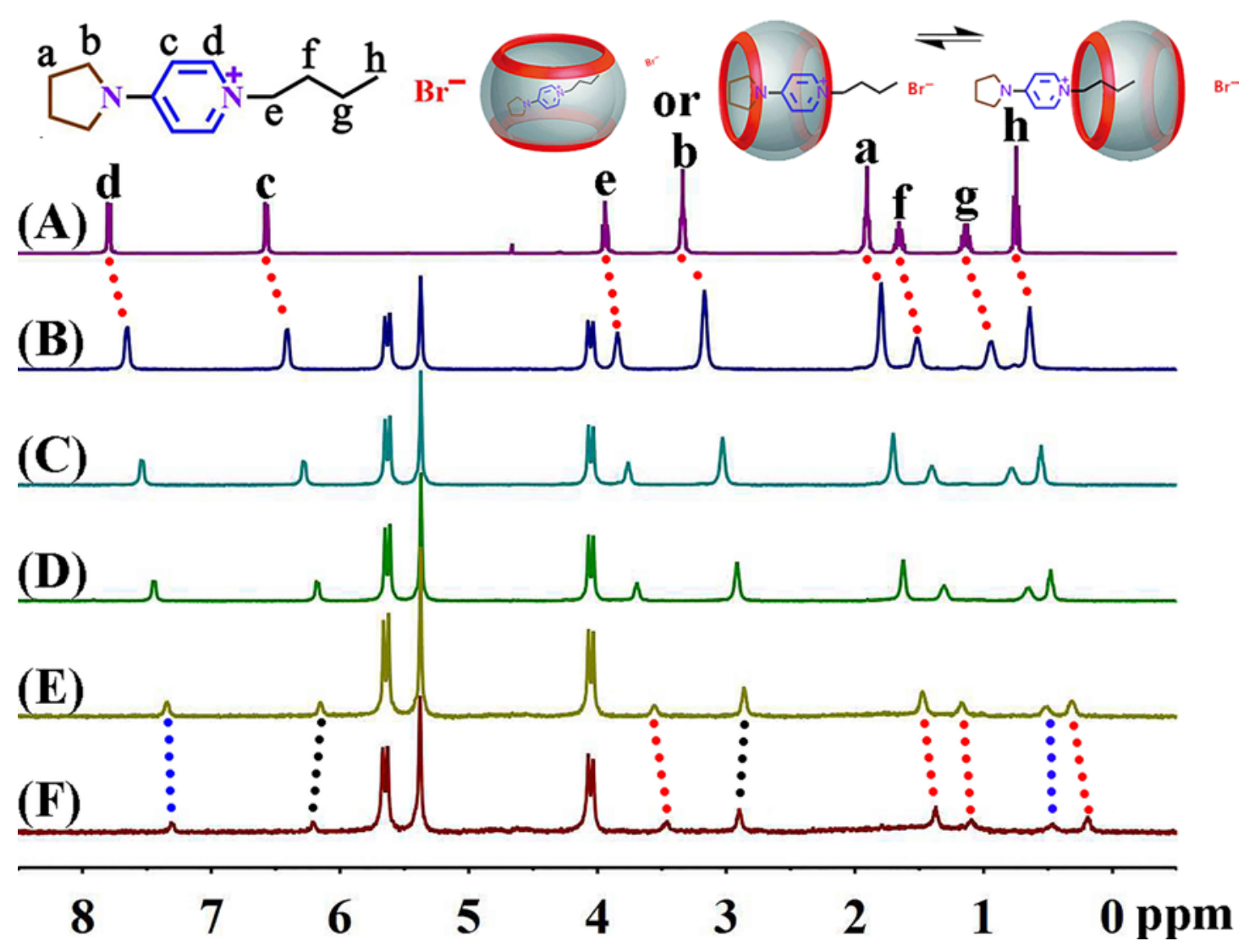

Figure 2. Interaction of g2 and $\mathrm{Q}[10]\left(20{ }^{\circ} \mathrm{C}\right):{ }^{1} \mathrm{H}$ NMR spectra $\left(400 \mathrm{MHz}, \mathrm{D}_{2} \mathrm{O}\right)$ of g2 
(ca. $2 \mathrm{mM}$ ) in the absence of Q[10] (A), in the presence of 0.169 equiv. of $\mathrm{Q}[10]$ (B), in the presence of 0.330 equiv. of $\mathrm{Q}[10](\mathrm{C})$, in the presence of 0.565 equiv. of $\mathrm{Q}[10]$ (D), in the presence of 0.963 equiv. of Q[10] (E) and in the presence of 1.372 equiv. of $\mathrm{Q}[10](\mathrm{F})$.

In the case of g4 (and g5), again all peaks undergo an up-field shift with shifts in the range 0.31 to $0.63 \mathrm{ppm}$ (for g4) and 0.25 to $0.66 \mathrm{ppm}$ (for g5), with the largest shift exhibited by Hg Hi (for g4) and $\mathrm{H}_{1}$ (for g5), Figure 3 and S8.
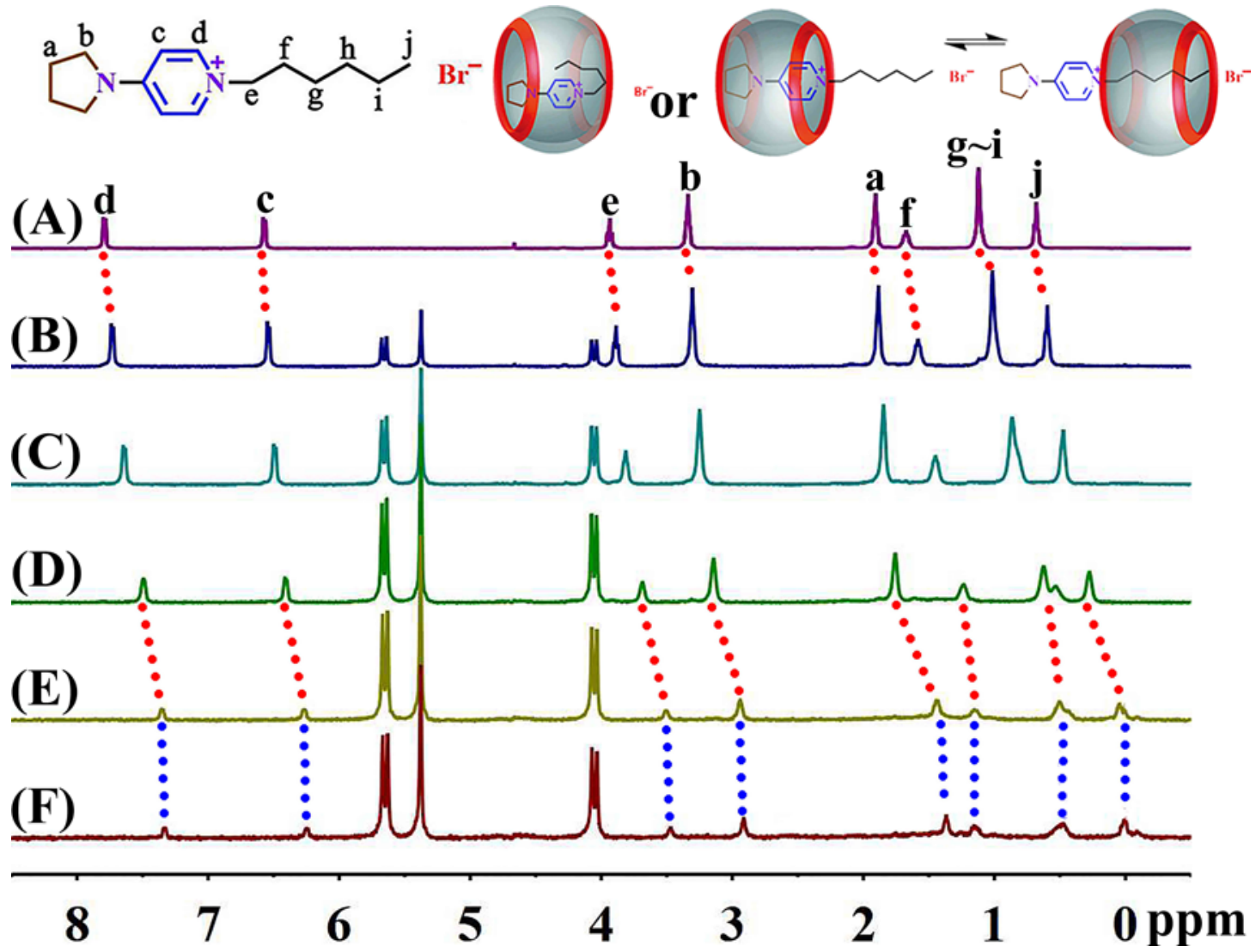

Figure 3. Interaction of g4 and $\mathrm{Q}[10]\left(20^{\circ} \mathrm{C}\right):{ }^{1} \mathrm{H}$ NMR spectra $\left(400 \mathrm{MHz}, \mathrm{D}_{2} \mathrm{O}\right)$ of g4 (ca. $2 \mathrm{mM}$ ) in the absence of Q[10] (A), in the presence of 0.078 equiv. of Q[10] (B), in the presence of 0.206 equiv. of $\mathrm{Q}[10](\mathrm{C})$, in the presence of 0.466 equiv. of $\mathrm{Q}[10]$ (D), in the presence of 1.014 equiv. of Q[10] (E) and in the presence of 1.303 equiv. of 
$\mathrm{Q}[10](\mathrm{F})$.

In the case of the largest guest g6, as shown in Figure 4, the alkyl chain is completely embedded in the cavity as evidenced by the mostly large up-field shifts exhibited by He-Hp (0.26-0.50), whereas Ha undergoes a slight down-field shift (0.05 ppm) and $\mathrm{Hb}$ and Hc exhibit only small up-field shifts (0.17 and 0.15 ppm respectively). These observations indicate that the tetrahydropyrrole moiety remains outside of the portal. For comparison, the chemical shifts of all the protons in these systems are presented in Table 1.

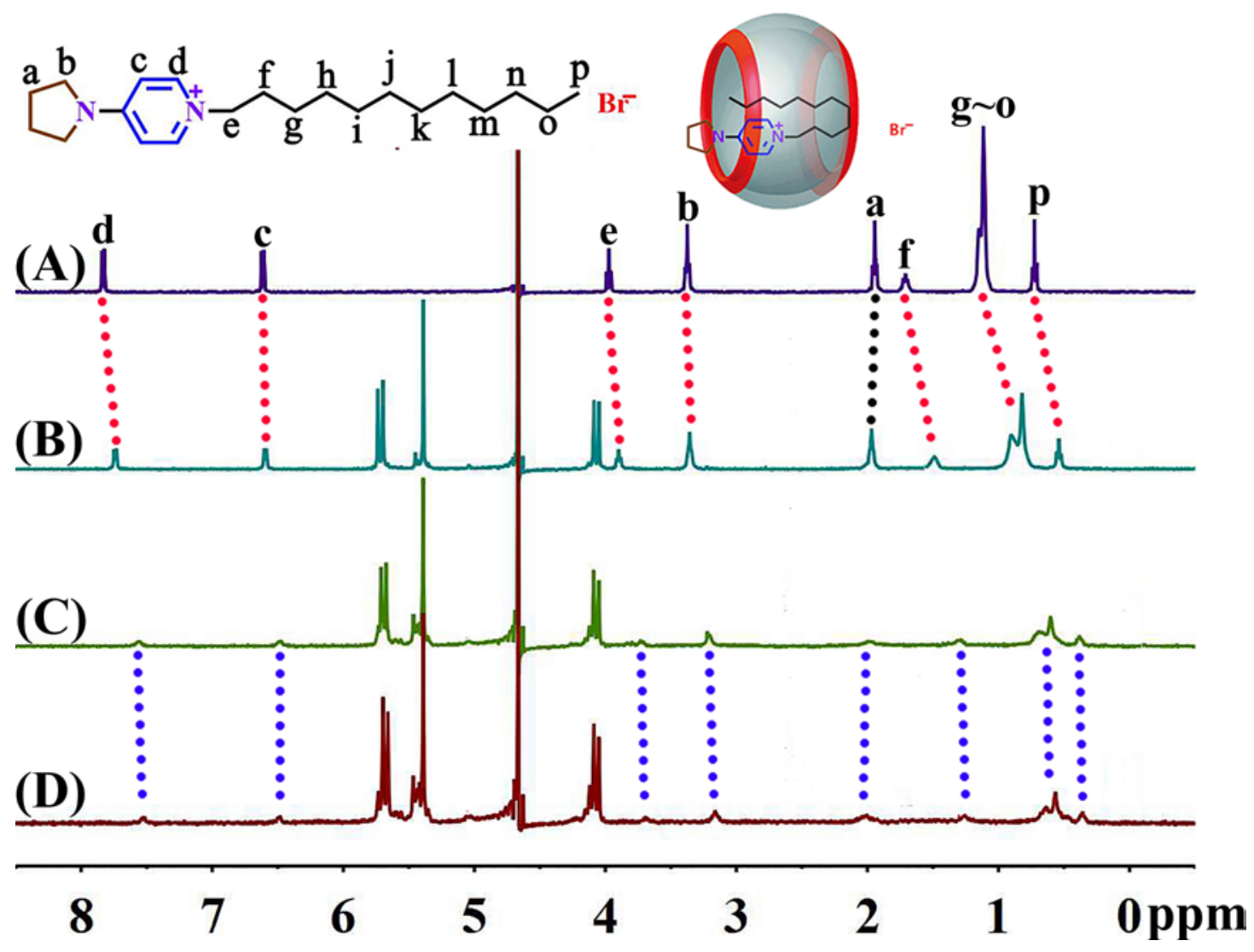

Figure 4. Interaction of g4 and $\mathrm{Q}[10]\left(20{ }^{\circ} \mathrm{C}\right):{ }^{1} \mathrm{H}$ NMR spectra $\left(400 \mathrm{MHz}, \mathrm{D}_{2} \mathrm{O}\right)$ of g6 (ca. $2 \mathrm{mM}$ ) in the absence of Q[10] (A), in the presence of 0.342 equiv. of Q[10] (B), in the presence of 1.045 equiv. of Q[10] (C) and in the presence of 1.934 equiv. of Q[10] 
(D).

\begin{tabular}{|c|c|c|c|c|c|}
\hline g1 & \multirow{2}{*}{$\Delta \delta / \mathrm{ppm}$} & g2 & \multirow{2}{*}{$\Delta \delta / \mathrm{ppm}$} & g3 & \multirow{2}{*}{$\Delta \delta / \mathrm{ppm}$} \\
\hline Protons & & Protons & & Protons & \\
\hline $\mathbf{a}$ & -0.5 & $\mathbf{a}$ & -0.54 & $\mathbf{a}$ & -0.54 \\
\hline b & -0.58 & b & -0.43 & b & -0.43 \\
\hline c & -0.47 & c & -0.37 & c & -0.34 \\
\hline d & -0.42 & d & -0.5 & d & -0.51 \\
\hline e & -0.38 & $\mathbf{e}$ & -0.46 & $\mathbf{e}$ & -0.45 \\
\hline \multirow[t]{3}{*}{ f } & -0.37 & f & -0.55 & f & -0.53 \\
\hline & & g & -0.68 & $\mathbf{i}$ & -0.59 \\
\hline & & h & -0.56 & g h & $\begin{array}{c}-0.59 \\
0.77\end{array}$ \\
\hline g4 & \multirow{2}{*}{$\Delta \delta / \mathrm{ppm}$} & g5 & \multirow{2}{*}{$\Delta \delta / \mathrm{ppm}$} & g6 & \multirow{2}{*}{$\Delta \delta / \mathrm{ppm}$} \\
\hline Protons & & Protons & & Protons & \\
\hline $\mathbf{a}$ & -0.47 & $\mathbf{a}$ & -0.56 & $\mathbf{a}$ & +0.05 \\
\hline b & -0.41 & b & -0.41 & b & -0.17 \\
\hline c & -0.31 & c & -0.25 & c & -0.15 \\
\hline d & -0.45 & d & -0.37 & d & -0.27 \\
\hline e & -0.43 & e & -0.51 & e & -0.26 \\
\hline f & -0.52 & f & -0.53 & f & -0.43 \\
\hline $\mathbf{j}$ & -0.62 & I & -0.66 & $\mathbf{p}$ & -0.36 \\
\hline $\mathbf{g} \mathbf{i}$ & -0.63 & $g \sim k$ & $\begin{array}{cc}-0.66 & - \\
0.71 & -0.88\end{array}$ & g $\mathbf{0}$ & -0.5 \\
\hline
\end{tabular}

Table 1. ${ }^{1} \mathrm{H}$ NMR complexation-induced shifts ( $\left.\Delta \delta / \mathrm{ppm}\right)$ of guest g1- g6 upon addition of Q[10] in $\mathrm{D}_{2} \mathrm{O}$ at $298 \mathrm{~K}$.

\subsection{UV spectroscopy}

Electronic absorption spectroscopy can be utilized to afford information about the binding mode(s) among the host and/or guest molecules, and so to further understand the binding of these 4-pyrrolidinopyridinium salts to Q[10], we employed UV-vis spectrometry herein. The UV spectra were obtained using aqueous solutions containing a fixed concentration of guest g1-g6 and 1.00 equiv. of Q[10]. As shown in Figure 5, the addition of 1.0 equiv. of Q[10] to the solution of the guest in water induces similar phenomena in the six systems. In particular, the guests 1-6 exhibited a maximum UV absorption at $282 \mathrm{~nm}$ in aqueous media on addition of Q[10] (1.0 equiv.) which resulted in a slight red shift, and the UV absorption intensity decreased significantly. 
These observations indicate that the interaction between $\mathrm{Q}[10]$ and guest 1-6 has occurred.

(A)

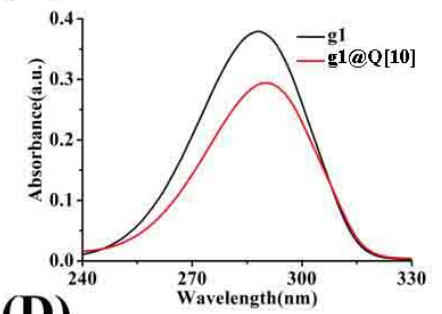

(D)

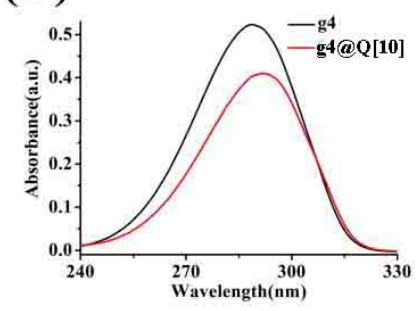

(B)

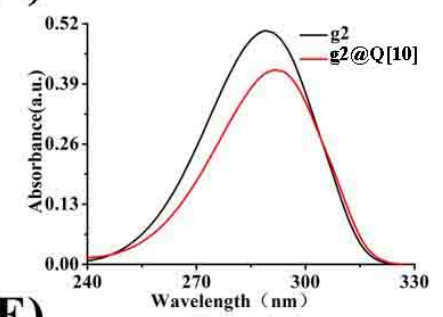

(E)

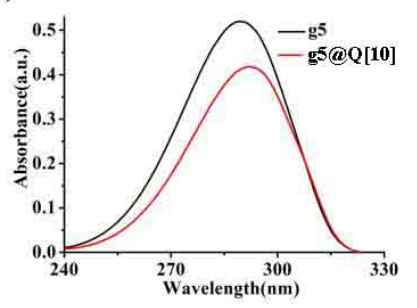

(C)
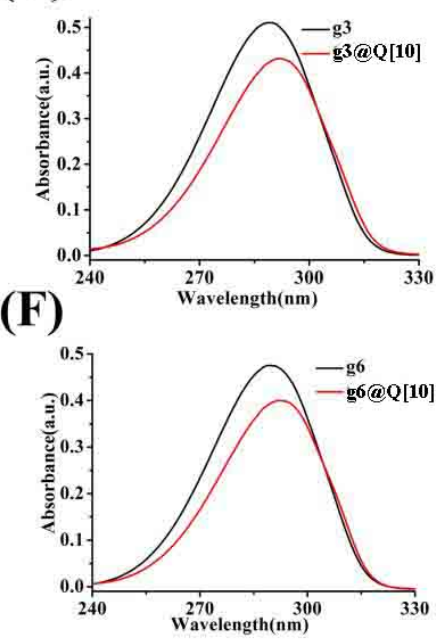

Figure 5. Electronic absorption of guests g1 to g6 and on addition of Q[10].

\subsection{Mass spectrometry}

The nature of the inclusion complexes between Q[10] and the 4-pyrrolidinopyridinium guests was also established by the use of MALTI-TOF mass spectra, as shown in Figure 6. Intense signals were found at 1838.68, 1866.74, 1880.76, 1894.79, 1922.83 and 1978.94, which correspond to [(g1@Q[10])-Br- $]^{+}$, [(g2@Q[10])-Br $]^{+},[(g 3 @ Q[10])-$ $\left.\mathrm{Br}^{-}\right]^{+},\left[(\mathrm{g} 4 @ \mathrm{Q}[10])-\mathrm{Br}^{-}\right]^{+},\left(\left[(\mathrm{g} 5 @ \mathrm{Q}[10])-\mathrm{Br}^{-}\right]^{+}\right.$and $\left(\left[(\mathrm{g} 6 @ \mathrm{Q}[10])-\mathrm{Br}^{-}\right]^{+}\right.$respectively, thereby providing support for the formation of 1:1 host-guest inclusion complexes. 
Figure 6. MALDI-TOF mass spectrometry of g1@Q[10] (A), g2@Q[10] (B), g3@Q[10] (C), g4@Q[10] (D),g5@Q[10] (E) and g6@Q[10] (F).

\subsection{DFT calculations}

We conducted first-principles calculations based on density functional theory $(\mathrm{DFT})^{[43,44]}$ to obtain the binding energy and the atomic structure of the pyrrolidinopyridinium guests in Q[10]. The binding energy will confirm the observed stability of the guest inside the Q[10], while the atomic structure will show the differences in the structure of the guest. We used a supercell approach, in which the guest and the host are placed in a (24x24x24)-sized unit cell. The diameter of the model $\mathrm{Q}[10]$ is $12.801 \AA$ and the width is $6.215 \AA$ as shown in Figure $7(\mathrm{~A})$ and Figure 7 (B), thus, the chosen unit cell size is enough to prevent interaction with periodic images. We used the projector-augmented-wave (PAW) method $^{[45]}$ to treat the ion-electron interaction and the Perdew-Burke-Ernzerhof functional (GGA-PBE) ${ }^{[46]}$ to describe the exchange and correlation effects. Because of the presence of oxygen and carbon in the guest/host system, a large $400 \mathrm{eV}$ plane wave cut-off energy is used. The molecular structure of both the guest and the host only necessitates a 1x1x1 K-point. All the DFT calculations are implemented in the Vienna Ab-initio Simulation Package (VASP). ${ }^{[47,}$ ${ }^{48]}$ The above calculation method and parameters are tested on pyridine and we have found a $1.343 \AA \mathrm{C}-\mathrm{N}, 1.395 \AA \mathrm{C}-\mathrm{C}$ and $1.091 \AA \mathrm{C}-\mathrm{H}$ bond lengths in agreement with experiment (1.340 $\AA, 1.396 \AA, 1.086 \AA) .{ }^{[49]}$ The obtained bond angles, which are $120.572^{\circ}$ for $\angle \mathrm{H}-\mathrm{C}-\mathrm{C}, 117.047^{\circ}$ for $\angle \mathrm{C}-\mathrm{N}-\mathrm{C}, 123.697^{\circ}$ for $\angle \mathrm{C}-\mathrm{C}-\mathrm{N}$, and $118.427^{\circ}$ for $\angle \mathrm{C}-\mathrm{C}$ C, are also in good agreement with experiment $\left(120.780^{\circ}, 116.980^{\circ}, 123.790^{\circ}\right.$, $\left.118.500^{\circ}\right)^{[46]}$, confirming the suitability and robustness of the employed theoretical methods.

Three guests are considered namely, g1, g2 and g3 and the optimized structures are depicted in Figure 7(C)-(E).
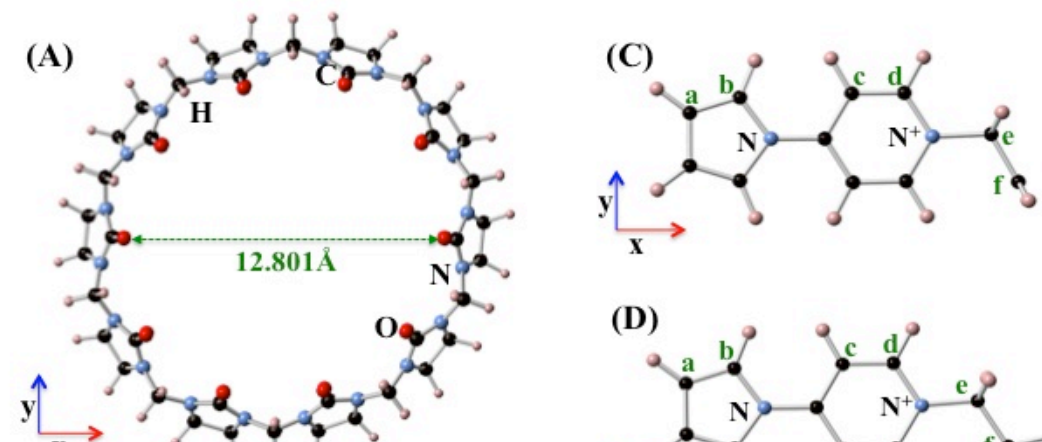

(D) 
Figure 7. Optimized atomic structure of Q[10] viewed along the center axis (A), perpendicular to the center axis (B), and of the guests, g1 (C), g2 (D) and g3 (E), viewed at the x-y plane. Relevant $\mathrm{C}$ atoms in the pyridine and pyrrole rings are labeled as a d, while those of the alkyl chains are indicated as $\mathbf{e} \sim \mathbf{i}$.

Although, three other larger guests (g4-g6) are not included in the DFT calculations due to their very large size requiring a much larger diameter and width for the host, the trends on the interaction can still be well captured. The guests are placed parallel to the center axis of the host (z-axis) and all the 205 atoms in g1/Q[10], 211atoms in g2/Q[10] and 214 atoms in $\mathrm{g} 3 / \mathrm{Q}[10]$ are allowed to relax using the conjugate-gradient algorithm until convergence is achieved, that is, when the forces on the atoms are $\sim 0.01 \mathrm{eV} / \AA$. The optimized guest/host structures are shown in Figure 8, and the binding energies $\left(E_{b}\right)$ are given in Table 2. $\mathrm{E}_{\mathrm{b}}$ is calculated with respect to the isolated guest and isolated host.

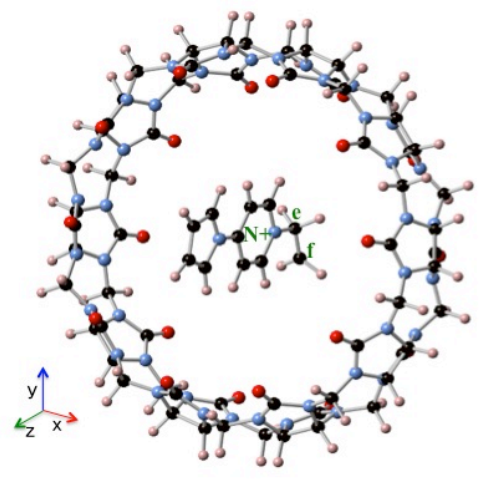

(A)

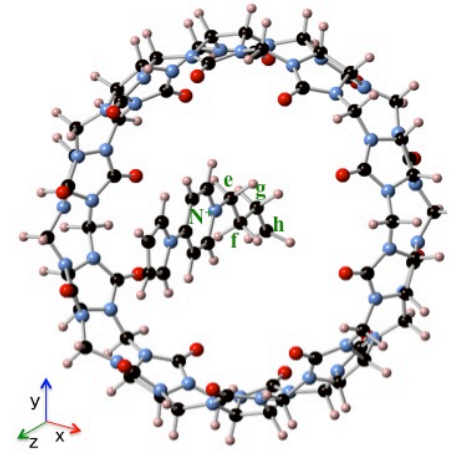

(B)

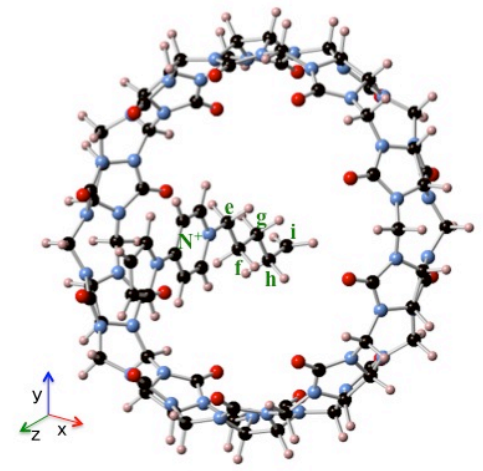

(C) 
Figure 8. Optimized atomic structure of g1 in Q[10] (A), g2 in Q[10] (B) and g3 in Q[10] (C).

We note that the binding energies are all negative, indicating stability of the guests inside the Q[10]. Because of the obvious curvature of the alkyl chains as seen on the empirical diagrams above, we obtained the $\mathbf{N}^{+}$-e-f and $\mathbf{f - g}-\mathbf{h}$ angles, which can quantitatively confirm the curvature as the chains become longer. These angles are given in Table 2. We note that for all guests, $\mathbf{N}^{+}$-e-f decreases when the host encapsulates the guests. For g2 and g3, the $\mathbf{f}-\mathbf{g}-\mathbf{h}$ angle also decreases. Thus, we can see the curving of the chains towards the -y axis in Figure 8. The changes in these angles led to contraction or elongation in the N-C and C-C bonds (please see Table 2). In the case of g1, $\mathbf{N}^{+}$-e decreases. For g2 and g3, an alternating decrease-increase in the last three C-C bonds (i.e. from e-f and f-g for g2 and g3, respectively) are noted. We think that such alternating contraction and elongation of bond lengths compensates for the significant decrease in the bond angles for g2 and g3.

\begin{tabular}{ccccccc}
\hline & g1 & g1/Q[10] & g2 & g2/Q[10] & g3 & g3/Q[10] \\
\hline $\mathbf{E}_{\mathbf{b}} \mathbf{( e V )}$ & - & -0.134 & - & -1.017 & - & -2.527 \\
$\angle \mathbf{N}^{+}-\mathbf{e}-\mathbf{f}\left(\mathbf{(}^{\circ}\right)$ & 117.030 & $116.706(\downarrow)$ & 118.428 & $116.483(\downarrow)$ & 119.037 & $117.021(\downarrow)$ \\
$\angle \mathbf{f}-\mathbf{g}-\mathbf{h}\left(\mathbf{(}^{\circ}\right)$ & - & - & 115.297 & $113.798(\downarrow)$ & 114.855 & $112.896(\downarrow)$ \\
$\mathbf{N}^{+}-\mathbf{e}$ & 1.539 & $1.538(\downarrow)$ & 1.515 & 1.515 & 1.513 & $1.515(\uparrow)$ \\
$\mathbf{e - f}$ & 1.475 & 1.475 & 1.527 & $1.528(\uparrow)$ & 1.530 & $1.528(\downarrow)$ \\
$\mathbf{f - g}$ & - & - & 1.565 & $1.561(\downarrow)$ & 1.536 & $1.530(\downarrow)$ \\
$\mathbf{g}-\mathbf{h}$ & - & - & 1.471 & $1.473(\uparrow)$ & 1.557 & $1.560(\uparrow)$ \\
$\mathbf{h}-\mathbf{i}$ & - & - & - & - & 1.477 & $1.472(\downarrow)$ \\
\hline
\end{tabular}

Table 2. Binding energy $\left(\mathbf{E}_{\mathbf{b}}\right)$ of the guests in the $\mathrm{Q}[10]$ and angles/distances between nitrogen and the carbon atoms of the alkyl chain. These atoms are depicted in Figure 8. Down (up) arrows indicate decrease (increase) with respect to that of the isolated guest molecule.

\section{Experimental Section}

\subsection{General remarks}

To analyze the host-guest complexation between Q[10] and g1/g2/g3/g4/g5/g6, $2.0-2.5 \times 10^{-3} \mathrm{mmol}$ solutions of $\mathrm{Q}[10]$ in $0.5-0.7 \mathrm{~mL} \mathrm{D}_{2} \mathrm{O}$ with $\mathrm{Q}[10]$ : g1/g2/g3/g4/g5/g6 ratios ranging between 0 and 2 were prepared. All ${ }^{1} \mathrm{H}$ NMR spectra, including those for the titration experiments, were recorded at $298.15 \mathrm{~K}$ on a JEOL JNM-ECZ400S $400 \mathrm{MHz}$ NMR spectrometer (JEOL) in $\mathrm{D}_{2} \mathrm{O}$. $\mathrm{D}_{2} \mathrm{O}$ 
was used as a field-frequency lock, and the observed chemical shifts are reported in parts per million (ppm). All UV-visible spectra were recorded from samples in $1 \mathrm{~cm}$ quartz cells on an Agilent 8453 spectrophotometer, equipped with a thermostat bath (Hewlett Packard, California, USA). The host and guests were dissolved in distilled water. UV-visible spectra were obtained at $25{ }^{\circ} \mathrm{C}$ at a concentration of $2.00 \times 10^{-5} \mathrm{~mol} \cdot \mathrm{L}^{-1}$ gi $(\mathrm{i}=1,2,3,4,5,6)$ and 1.00 equiv. $\mathrm{Q}[10]$ concentrations for the Q[10]@gi (i=1,2,3,4,5,6) system. MALDI-TOF mass spectrometry was recorded on a Bruker BIFLEX III ultra-high resolution Fourier transform ion cyclotron resonance (FT-ICR) mass spectrometer with a-cyano-4hydroxycinnamic acid as matrix. 4-pyrrolidinopyridine was purchased from Aladdin Industrial Corporation, and Q[10] was prepared and purified according to previously published methods. (29) All other reagents were of analytical grade and were used as received. Double-distilled water was used for all experiments.

\subsection{Synthesis of guest g1}

4-pyrrolidinopyridine (296 mg, $0.002 \mathrm{~mol}$ ) and bromoethane (1.308 g, $0.012 \mathrm{~mol}$ ) were dissolved in acetonitrile $(40 \mathrm{ml})$. The solution was stirred under an inert nitrogen atmosphere and heated to $80{ }^{\circ} \mathrm{C}$ and refluxed for $12 \mathrm{~h}$. The resulting solution was filtered and then the yellow precipitate was washed with diethyl ether and then dried in vacuo to give g1 (437 mg, 85\%). ${ }^{1} \mathrm{H}$ NMR ( $\mathrm{D}_{2} \mathrm{O}, 400$ MHz) $\delta 7.78$ (d, J = 7.6 Hz, 2H), 6.54 (d, J = 7.5 Hz, 2H), 3.94 (q, J = $7.3 \mathrm{~Hz}$, 2H), 3.30 (m, J = 8.0 Hz, 4H), $1.90-1.84$ (m, 4H), 1.25 (t, J = 7.3 Hz, 3H). Anal. Calcd. for $\mathrm{C}_{11} \mathrm{H}_{17} \mathrm{~N}_{2} \mathrm{Br}$ : C, 51.37; H, 6.66; N, 10.89; found C, 51.29; H, 6.71; N, 10.92.

\subsection{Synthesis of guest $g 2$}

As for g1, but using 4-pyrrolidinopyridine (296 mg, $0.002 \mathrm{~mol}$ ) and bromobutane (1.644 g, 0.012mol) to give g2 (496 mg, 87\%). ${ }^{1} \mathrm{H}$ NMR $\left(\mathrm{D}_{2} \mathrm{O}, 400 \mathrm{MHz}\right) \delta 7.79$ (d, J = 7.6 Hz, 2H), 6.57 (d, J = $7.5 \mathrm{~Hz}, 2 \mathrm{H}), 3.94$ (t, J = $7.1 \mathrm{~Hz}, 2 \mathrm{H}), 3.34$ (t, J = $6.7 \mathrm{~Hz}, 4 \mathrm{H}), 1.93-1.88(\mathrm{~m}, 4 \mathrm{H}), 1.66$ (m, J = $14.8 \mathrm{~Hz}, 2 \mathrm{H}), 1.14$ (m, J = 14.8 $\mathrm{Hz}, 2 \mathrm{H}$ ), 0.75 (t, J = 7.4 Hz, 3H). Anal. Calcd. for $\mathrm{C}_{13} \mathrm{H}_{21} \mathrm{~N}_{2} \mathrm{Br}$ : C, $54.74 ; \mathrm{H}$, 
7.42; N, 9.82; found C, 54.82; H, 7.47; N, 9.75.

\subsection{Synthesis of guest g3}

As for g1, but using 4-pyrrolidinopyridine (296 mg, $0.002 \mathrm{~mol}$ ) and bromopentane (1.813 g, 0.012mol) to give g3 (508 mg, 85\%). ${ }^{1} \mathrm{H}$ NMR $\left(\mathrm{D}_{2} \mathrm{O}\right.$, $400 \mathrm{MHz}$ ) $\delta 7.75$ (d, J = 7.6 Hz, 2H), 6.53 (d, J = 7.6 Hz, 2H), 3.90 (t, J = 7.1 Hz, 2H), 3.30 (t, J = $6.8 \mathrm{~Hz}, 4 \mathrm{H}), 1.89-1.84(\mathrm{~m}, 4 \mathrm{H}), 1.64(\mathrm{~m}, \mathrm{~J}=14.5 \mathrm{~Hz}, 2 \mathrm{H})$, $1.18-0.99(\mathrm{~m}, 4 \mathrm{H}), 0.66(\mathrm{t}, \mathrm{J}=8.8 \mathrm{~Hz}, 3 \mathrm{H})$. Anal. Calcd. for $\mathrm{C}_{14} \mathrm{H}_{23} \mathrm{~N}_{2} \mathrm{Br}$ : C, 56.19; H, 7.75; N, 9.36; found C, 56.14; H, 7.81; N, 9.39.

\subsection{Synthesis of guest g4}

As for g1, but using 4-pyrrolidinopyridine (296 mg, $0.002 \mathrm{~mol}$ ) and bromohexane (1.981 g, 0.012mol) to give g4 (551 mg, 88\%). ${ }^{1} \mathrm{H}$ NMR $\left(\mathrm{D}_{2} \mathrm{O}\right.$, $400 \mathrm{MHz}$ ) $\delta 7.79$ (d, J = 7.0 Hz, 2H), 6.57 (d, J = $7.1 \mathrm{~Hz}, 2 \mathrm{H}$ ), 3.94 (q, J = 7.0 Hz, 2H), 3.35 (d, J = 6.1 Hz, 4H), 1.91 (m, 4H), 1.68 (m, J = 6.6 Hz, 2H), 1.12 (m, 6H), 0.69 (t, J = 6.4 Hz, 3H). Anal. Calcd. for $\mathrm{C}_{15} \mathrm{H}_{25} \mathrm{~N}_{2} \mathrm{Br}$ : C, 57.51; H, 8.04; N, 8.94; found C, 57.48; H, 8.11; N, 8.99.

\subsection{Synthesis of guest g5}

As for g1, but using 4-pyrrolidinopyridine (296 mg, $0.002 \mathrm{~mol}$ ) and 1bromooctane (2.318 g, 0.012mol) to give g5 (593 mg, 87\%). ${ }^{1} \mathrm{H}$ NMR ( $\mathrm{D}_{2} \mathrm{O}, 400$ MHz) $\delta 7.79$ (d, J = 7.0 Hz, 2H), 6.57 (d, J = 7.1 Hz, 2H), 3.94 (t, J = 7.0 Hz, 2H), 3.35 (d, J = 6.1 Hz, 4H), 1.91 (m, 4H), 1.68 (m, J = 6.6 Hz, 2H), 1.12 (m, $10 \mathrm{H}$ ), 0.69 (t, J = 6.4 Hz, 3H). Anal. Calcd. for $\mathrm{C}_{17} \mathrm{H}_{29} \mathrm{~N}_{2} \mathrm{Br}$ : C, 59.82; H, 8.56; N, 8.21; found C, 59.89; H, 8.59; N, 8.14.

\subsection{Synthesis of guest g6}

As for g1, but using 4-pyrrolidinopyridine (296 mg, $0.002 \mathrm{~mol}$ ) and 1bromododecane (2.991 g, 0.012mol) to give g6 (659 mg, 83\%). ${ }^{1} \mathrm{H}$ NMR ( $\mathrm{D}_{2} \mathrm{O}$, $400 \mathrm{MHz}$ ) $\delta 7.81$ (d, J = 7.3 Hz, 2H), 6.59 (d, J = 7.4 Hz, 2H), 3.95 (t, J = 6.9 Hz, 2H), 3.35 (t, J = 6.4 Hz, 4H), 1.93 (m, J = 6.7 Hz, 4H), 1.70 (d, J = 6.9 Hz, 2H), 1.11 (m, 18H), 0.70 (t, J = 6.7 Hz, 3H). Anal. Calcd. for $\mathrm{C}_{21} \mathrm{H}_{37} \mathrm{~N}_{2} \mathrm{Br}$ : C, 63.46; H, 9.38; N, 7.05; found C, 63.40; H, 9.42; N, 7.10. 


\section{Conclusion}

In summary, we have conducted spectroscopic investigations of the interaction between $\mathrm{Q}[10]$ and 4-pyrrolidinopyridinium salts 4- $\left(\mathrm{C}_{4} \mathrm{H}_{8} \mathrm{~N}\right) \mathrm{C}_{5} \mathrm{H}_{5} \mathrm{NRBr}$, where $\mathrm{R}=\mathrm{Et}$ (g1), $n$ butyl (g2), n-pentyl (g3), n-hexyl (g4), n-octyl (g5), n-dodecyl (g6). Results revealed that the guests g1-g5 are located completely inside the cavity differing only in their orientation with g1, g4 and g5 aligned with the portal whilst g2 and g3 are perpendicular to it. For g6, the tetrahydropyrrole moiety remains outside of the portal. Calculations suggest that the guests are stable in the Q[10] host and that the curvature of the alkyl chain increases as the length of the chain increases.

\section{Acknowledgement (Funding)}

Financial support from the National Natural Science Foundation of China (NSFC no 21861011), the Major Program for Creative Research Groups of Guizhou Provincial Education Department (2017-028), the Science and Technology Fund of Guizhou Province (No. 2016-1030, 2018-5781) and the Innovation Program for High-level Talents of Guizhou Province (No. 2016-5657) are gratefully acknowledged. CR thanks the EPSRC for an Overseas Travel Grant (No. EP/R023816/1). MCE acknowledges financial support from UF for the use of the Kyoto Supercomputer (ACCMS).

\section{Disclosure statement}

No potential conflict of interest was reported by the authors. 


\section{References}

[1] Isaacs, L. Chem. Commun. 2009, 619-629.

[2] Isaacs, L. Isr. J. Chem. 2011, 51, 578 - 591.

[3] Das, D.; Scherman, O. A.; Isr. J. Chem. 2011, 51, 537 - 550.

[4] Masson, E.; Ling, X.; Joseph, R.; Kyeremeh-Mensah, L.; Lu, X. RSC Adv. 2012, 2, 1213-1247.

[5] Ni, X. - N.; Xiao, X.; Cong, H. Liang, L. - L.; Cheng, K.; Cheng, X. - J.; Ji, N. - N.; Zhu, Q. - - J.; Xue, S. - F.; Tao, Z. Chem. Soc. Rev. 2013, 42, 9480-9508.

[6] Assaf K. I.; Nau, W. M. Chem. Soc. Rev. 2015, 44, 394-418.

[7] Barrow, S. J.; Kasera, S.; Rowland, M. J.; del Barrio, J.; Scherman, O. A. Chem. Rev. 2015, 115, 12320-12406.

[8] Fang, G. S.; Sun, W. Q.; Zhao, W. X,; Lin, R. L.; Tao, Z.; Liu, J. X. Org. Biomol. Chem. 2016, 14, 674-679.

[9] Lin, R. L.; Li, J. Q.; Liu, J. X.; Kaifer, A. E.. J. Org. Chem. 2015, 80, 1050510511

[10] S. Liu, S.; Shukla, A. D.; Gadde, S.; Wagner, B. D.; Kaifer, A. E.; Isaacs, L. Angew. Chem. Int. Ed. 2008, 47, 2657 - 2660.

[11] Park, K. M.; Roh, J. H.; Sung, G.; Murray, J.; Kim, K. Chem. Asian J. 2017, 12, $1461-1464$.

[12] Liu, S.; Zavalij, P. Y.; Isaacs, L. J. Am. Chem. Soc. 2005, 127, 16798-16799.

[13] Kuang, S.; Hu, Z.; Zhang, H.; Zhang, X.; Liang, F.; Zhao, Z.; Liu, S. Chem. Commun. 2018, 54, 2169-2172. 
[14] Li, F.; Gorle, A. K.; Ranson, M.; Vine, K. L.; Kinobe, R.; Feterl, M.; Warner, J.

M.; Keene, F. R.; Collins, J. G.; Day, A. I. Org. Biomol. Chem. 2017, 15, 4172-4179.

[15] Alrawashdeh, L. R.; Cronin, M. P.; Day, A. I.; Wallace, L.; Woodward, C. E. Analyst, 2018, 143, 519-527.

[16] Day, A. I.; Blanch, R. J.; Arnold, A. P.; Lorenzo, S.; Lewis, G. R.; Dance, I. Angew. Chem. 2002, 114, 285-287.

[17] Liu, J. - X.; Lin, R. - L.; Long, L. - S.; Huang, R. - B.; Zheng, L. - S. Inorg. Chem. Commun. 2008, 11, 1085 - 1087.

[18] Pisani, M. J.; Zhao, Y.; Wallace, L.; Woodward, C. E.; Keene, F. R.; Day, A. I.; J. G. Collins, J. G.; Dalton Trans. 2010, 39, 2078 - 2086.

[19] Alrawashdeh, L. R.; Cronin, M. P.; Woodward, C. E.; Day, A. I.; Wallace, L. Inorg. Chem. 2016, 55, 6759-6769.

[20] Li, F.; Feterl, M.; Warner, J. M.; Day, A. I.; Keene, F. R.; Collins, J. G. Dalton Trans. 2013, 42, $8868-8877$.

[21] Alrawashdeh, L. R.; Day, A. I.; Wallace, L. Dalton Trans. 2013, 42, 16478 16481.

[22] X. J. Cheng, L. L. Liang, K. Chen, N. N. Ji, X. Xiao, J. X. Zhang, Y. Q. Zhang, S. F. Xue, Q. J. Zhu, X. L. Ni, Z. Tao, Angew. Chem., Int. Ed. 2013, 52, 7252.

[23]Q. Li, S. C. Qiu, J. Zhang, K. Chen, Y. Huang, X. Xiao, Y. Zhang, F. Li, Y. Q. Zhang, S. F. Xue, Q. J. Zhu, Z. Tao, L. F. Lindoy, G. Wei, Org. Lett. 2016, 18, 4020. [24]A. I. Day, R. J. Blanch, A. P. Arnold, S. Lorenzo, G. R. Lewis, I. Dance, Angew. Chem., Int. Ed. 2002, 41, 275. 
[25]M. J. Pisani, Y. Zhao, L. Wallace, C. E. Woodward, F. R. Keene, A. I. Day, J. G.

Collins, Dalton Trans. 2010, 39, 2078.

[26]S. Liu, P. Y. Zavalij, L. Isaacs, J. Am. Chem. Soc. 2005, 127, 16798.

[27]S. Liu, X. Yang, W. Gong, Method for preparing high-purity cucurbit[10]uril, Faming Zhuanli Shenqing 2015, CN 104557951.

[28]S. Liu, P. Y. Zavalij, Y. F. Lam, L. Isaacs, J. Am. Chem. Soc. 2007, 129, 11232.

[29]J. X. Liu, R. L. Lin, L. S. Long, R. B. Huang, L. S. Zheng, Inorg. Chem.

Commun. 2008, 11, 1085.

[30]S. Liu, A. D. Shukla, S. Gadde, B. D. Wagner, A. E. Kaifer, L. Isaacs, Angew.

Chem., Int. Ed. 2008, 47, 2697.

[31]F. Li, M. Feterl, J. M. Warner, A. I. Day, F. R. Keene, J. G. Collins, Dalton Trans. 2013, 42, 8868.

[32]L. R. Alrawashdeh, A. I. Day, L. Wallace, Dalton Trans. 2013, 42, 16478.

[31]L. R. Alrawashdeh, M. P. Cronin, C. E. Woodward, A. I. Day, L. Wallace, Inorg. Chem. 2016, 55, 6759.

[34] Chen,L. X.; Kan, J. L.; Cong, H.; Prior, T. J.; Tao, Z.; Xiao, X.; Redshaw, C. Molecules 2017, 22, 1147-1154.

[35] Ding, Y.; Yang, B.; Liu, H.; Liu, Z.; Zhang, X.; Liu, Q. Sensor Actuat B: Chem., 2018, 259, 775-783.

[36] Xia, Y.; Wang, C. - Z.; Tian, M.; Tao, Z.; Ni, X. - L.; Prior, T. J.; Redshaw, C. Molecules 2018, 23, 175.

[37] Bai, D.; Gao, Z.; Tao, Z.; Xiao, X.; Prior, T. J.; Wei, G.; Liu, Q.; Redshaw, C. New J. Chem. 2018, 42, 11085-11092. 
[38] Yamanaka, M.; Yoshida, U.; Sato, M.; Shigeta, T.; Yoshida, K.; Furuta, T.;

Kawabata, T. J. Org. Chem. 2015, 80, 3075 - 3082.

[39] Sammaki, T.; Hurley, T. B. J. Am. Chem. Soc. 1996, 118, 8967- 8968.

[40] Nguyen, H.V.; Butler, D.C.D.; Richards, C. J. Org. Lett. 2006, 8, 769-772

[41] Hou, H. -B.; Gao, Z. -Z.; Bai, D.; Tao, Z.; Prior, T. J.; Redshaw, C.; Xiao, X.

Supramol. Chem. 2017, 9, 680-685.

[42] Hou, H. -B.; Gao, Z. -Z.; Bai, D.; Tao, Z.; Prior, T. J.; Redshaw, C.; Xiao, X.

Supramol. Chem. 2017, 9, 680-685.

[43] Hohenberg P.; Kohn, W. Phys. Rev. B 1964, 136, B864-B871

[44] Kohn, W. ; Sham L. J. Phys. Rev. 1965, 140, A1133-A1138

[45] Blochl, P. Phys. Rev. B 1994, 50, 17953-17979

[46] Perdew, J. P.; Burke, K. ; Ernzerhof M. Phys. Rev. Lett. 1996, 77, 3865-3868.

[47] Kresse, G.; Hafner, J. Phys. Rev. B 1993, 47, 558-561

[48] Kresse, G.; Furthmuller, J. Phys. Rev. B 1996, 54, 11169-11186.

[49] Bock, C.W.; Trachtman, M. Chem. Phys. 1986, 105, 107-116. 


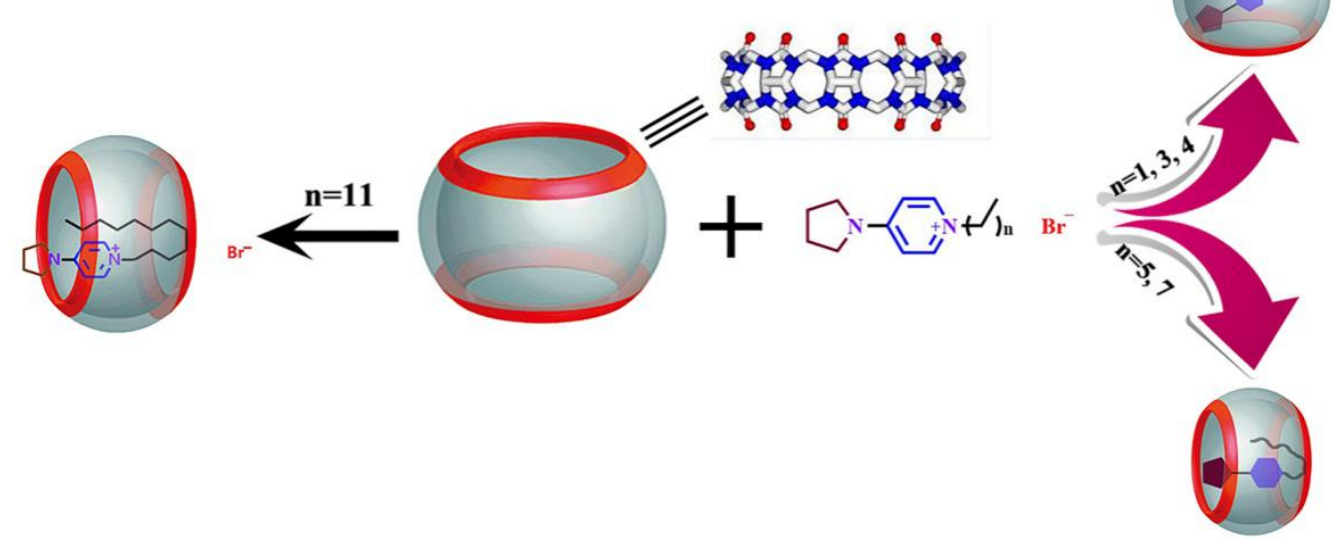

TOC 